\title{
Forced Nonuse in Unilateral Parkinsonian Rats Exacerbates Injury
}

\author{
Jennifer L. Tillerson, ${ }^{1}$ Ann D. Cohen, ${ }^{3}$ W. Michael Caudle, ${ }^{2}$ Michael J. Zigmond, ${ }^{3}$ Timothy Schallert, ${ }^{1,4}$ and \\ Gary W. Miller ${ }^{1,2}$ \\ 1/nstitute for Neuroscience and 2Division of Pharmacology and Toxicology, College of Pharmacy, University of Texas at \\ Austin, Austin, Texas 78712, ${ }^{3}$ Department of Neurology, University of Pittsburgh, Pittsburgh, Pennsylvania 15260, and \\ 4Department of Neurosurgery, University of Michigan, Ann Arbor, Michigan 48109
}

\begin{abstract}
Diagnosis of Parkinson's disease (PD) is based on the presentation of clinical symptoms such as bradykinesia, resting tremor, and rigidity. However, one feature of PD that often begins years before diagnosis is decreased physical activity. We hypothesized that this depressed activity is not only a symptom of the early dopaminergic loss but also a catalyst in the degenerative process. Two experiments were performed to test this hypothesis. First, rats were exposed to a mild dose of 6-hydroxydopamine unilaterally into the nigrostriatal dopamine (DA) projections, which would normally result in an $\sim 20 \%$ DA loss and no detectable behavioral asymmetries. A subset of these lesioned animals then had a cast applied for $7 \mathrm{~d}$ to the contralateral forelimb. After the cast was removed, these animals displayed long-term behavioral asymmetry and exacerbation of neurochemical loss ( $\sim 60 \%$ depletion). Second, a group
\end{abstract}

of animals received a high dose of 6-hydroxydopamine that normally would yield a severe loss of nigrostriatal terminals ( $\sim 90 \%$ loss) and chronic sensorimotor deficits. During the first $7 \mathrm{~d}$ after neurotoxin exposure, a subset of these animals were forced to rely on the contralateral forelimb, a procedure we have previously reported to protect DA terminals and behavioral function. Some of these rats then had the use of their "recovered" forelimb restricted during the second or third week after lesioning. This precipitated a severe and chronic loss of DA terminals and functional deficits. These results suggest decreased physical activity not only is a symptom of PD but also may act to potentiate the underlying degeneration.

Key words: Parkinson's disease; physical activity; dopamine; plasticity; dopamine transporter; vesicular monoamine transporter
Parkinson's disease (PD) is characterized by progressive motor impairment attributable primarily to degeneration of nigrostriatal dopamine (DA) neurons (for review, see Olanow and Tatton, 1999; Zigmond and Burke, 2002). In patients with PD, movement is difficult, and inactivity becomes more prominent as the DA neurons degenerate (Fertl et al., 1993; Comella et al., 1994; Toth et al., 1997; Mazzoni and Ford, 1999). Compensatory neurobiological changes and learned behavioral strategies may delay the appearance or detection of symptoms until the loss of terminals in the striatum becomes extensive enough to overcome the capacity of the system (Zigmond et al., 1984; Zigmond and Stricker, 1989; Lees, 1992; Zigmond, 1997; Swinnen et al., 2000). For example, early in the disease, patients may learn to adapt to their motor deficits by using alternate behavioral strategies that lead to even greater dependence on less compromised motor systems (Lees, 1992), an observation typical of animal neurological models and patients with other types of brain injury (Schallert and Hall, 1988; Lees, 1992; Jones and Schallert, 1994; Liepert et al., 2000; Schallert and Tillerson, 2000; Whishaw, 2000). Indeed, a decrease in motor activity often appears to precede frank neurological deficits (Fertl et al., 1993; Comella et al., 1994; Toth et al., 1997; Mazzoni and Ford, 1999).

We have shown recently that early forced use of the impaired

\footnotetext{
Received Feb. 26, 2002; revised May 6, 2002; accepted May 13, 2002.

This work was supported by National Institutes of Health Grants ES-09248 (G.W.M.), NS-37031 (G.W.M.), NS-23979 (T.S.), and NS-19608 (M.J.Z.). We thank Susan Slagel for technical assistance and helpful comments and Dr. Pat Randall for assistance with statistical processing.

Correspondence should be addressed to Dr. Gary W. Miller, Emory University Center for Neurodegenerative Diseases, Whitehead Building, Room 505, 615 Michael Street, Atlanta, GA 30322. E-mail: gwmille@emory.edu.

Copyright (C) 2002 Society for Neuroscience $0270-6474 / 02 / 226790-10 \$ 15.00 / 0$
}

forelimb in rats unilaterally depleted of striatal DA results in amelioration of behavioral deficits and substantial increases in striatal DA levels and vesicular monoamine transporter 2 (VMAT2) immunoreactivity (Tillerson et al., 2001). Consistent with these results, clinical application of physical therapy in the latter stages of PD results in improved function and life span (Bilowit, 1956; Knott, 1957; Franklyn et al., 1981; Szekely et al., 1982). The combination of physical activity leading to improvement in function and the observations of decreased physical activity early in PD suggests that the decreased physical activity not only may be a symptom of the degeneration but also may contribute to behavioral and neurochemical loss. In the following experiments, we tested the hypothesis that restraint of the affected forelimb in rats with mild subclinical unilateral lesions to the nigrostriatal system would result in exacerbation of the injury. In addition, we examined whether forced nonuse of the impaired forelimb could unmask or exaggerate an injury previously assumed to have recovered.

\section{MATERIALS AND METHODS}

Animals

Fifty-six hooded Long-Evans rats weighing between 350 and $450 \mathrm{gm}$ at the time of lesioning were used. Animals were housed in groups of three in clear Plexiglas cages containing sawdust, maintained on a $12 \mathrm{hr}$ light/dark cycle, and given food and water ad libitum. Animals were gently handled at least twice a week for 5 min for 1 month before surgery and behavioral testing. All handling and behavioral testing was performed during the animals' dark cycle. All procedures were approved by the Institutional Animal Care and Use Committee of the University of Texas at Austin in accordance with National Institutes of Health principles of laboratory animal care guidelines. 


\begin{tabular}{|c|c|c|c|c|}
\hline Lesion & Dose $(\mu \mathrm{g})$ & $n$ & Limb use manipulation & Behavior during cast period \\
\hline Unilateral MFB & 5 & 8 & No cast & Equal use of both forelimbs (symmetrical limb use) \\
\hline Unilateral MFB & 5 & 7 & Contralateral cast days $1-7$ & $\begin{array}{l}\text { Asymmetrical limb use; forced nonuse of the forelimb correspond- } \\
\text { ing to the lesioned hemisphere days } 1-7\end{array}$ \\
\hline Unilateral MFB & 10 & 8 & No cast & $\begin{array}{l}\text { Asymmetrical limb use; spontaneous preferential use of the forelimb } \\
\text { corresponding to the intact hemisphere }\end{array}$ \\
\hline Unilateral MFB & 10 & 7 & Ipsilateral cast days $1-7$ & $\begin{array}{l}\text { Asymmetrical limb use: forced reliance on the forelimb that corre- } \\
\text { sponds to the lesioned hemisphere days } 1-7\end{array}$ \\
\hline Unilateral MFB & 10 & 6 & $\begin{array}{l}\text { (1) Ipsilateral cast days } 1-7 \text {; (2) } \\
\text { contralateral cast days } 7-14\end{array}$ & $\begin{array}{l}\text { Asymmetrical limb use; }(1) \text { forced reliance on the limb correspond- } \\
\text { ing hemisphere days } 1-7 ;(2) \text { forced nonuse of the forelimb corre- } \\
\text { sponding to the lesioned hemisphere days } 7-14\end{array}$ \\
\hline Unilateral MFB & 10 & 6 & $\begin{array}{l}\text { (1) Ipsilateral cast days } 1-7 \text {; (2) } \\
\text { contralateral cast days } 21-28\end{array}$ & $\begin{array}{l}\text { Asymmetrical limb use; }(1) \text { forced reliance on the limb correspond- } \\
\text { ing to lesioned hemisphere days } 1-7 ;(2) \text { forced nonuse of the } \\
\text { forelimb corresponding to the lesioned hemisphere days } 21-28\end{array}$ \\
\hline Sham & 0 & 6 & No cast & Equal use of both limbs \\
\hline Sham & 0 & 4 & Ipsilateral cast days $1-7$ & $\begin{array}{l}\text { Asymmetrical limb use; forced use of limb corresponding to sham } \\
\text { operated hemisphere }\end{array}$ \\
\hline Sham & 0 & 4 & $\begin{array}{l}\text { (1) Ipsilateral cast days } 1-7 \text {; (2) } \\
\text { contralateral cast days } 7-14\end{array}$ & $\begin{array}{l}\text { Asymmetrical limb use; }(1) \text { forced use of the limb corresponding to } \\
\text { sham operated hemisphere days } 1-7 ;(2) \text { forced nonuse of the } \\
\text { forelimb corresponding to the lesioned hemisphere days } 7-14\end{array}$ \\
\hline
\end{tabular}

MFB, Medial forebrain bundle.

\section{Surgical procedures}

Animals were anesthetized with equithesin $(25 \mathrm{mg} / \mathrm{kg}$ pentobarbital; P3761; Sigma, St. Louis, MO) and $150 \mathrm{mg} / \mathrm{kg}$ chloral hydrate (0.35 $\mathrm{ml} / 100 \mathrm{gm}$, i.p.; C8383; Sigma) followed by atropine sulfate $(0.1 \mathrm{mg} / \mathrm{kg}$. i.p.; A0257; Sigma) to facilitate respiration before being placed in the stereotaxic apparatus. To protect noradrenergic neurons, animals also received desipramine $\mathrm{HCl}$ (15 mg/kg, i.p.; D3900; Sigma), a norepinephrine reuptake inhibitor, $30 \mathrm{~min}$ before the infusion of 6-hydroxydopamine hydrobromide (6-OHDA). Two categories of neurotoxin exposure were used: a mild dose of 6 -OHDA $(5 \mu \mathrm{g} / 4 \mu \mathrm{l})$ or a more severe dose of 6 -OHDA $(10 \mu \mathrm{g} / 4 \mu \mathrm{l}$, weight of 6 -OHDA; H8523; Sigma). The 6-OHDA, a selective neurotoxin for catecholamine neurons, was infused unilaterally $(0.5 \mu \mathrm{l} / \mathrm{min})$ into the medial forebrain bundle $(3.3 \mathrm{~mm}$ posterior and $1.8 \mathrm{~mm}$ lateral to bregma and $8.1 \mathrm{~mm}$ ventral to dura). Control-operated animals received all standard stereotaxic surgical procedures up to but not including lowering of the infusion cannula. After surgery, all animals were placed in an incubator to minimize hypothermia.

\section{Forelimb immobilization (casting) procedures and treatment groups}

Animals were randomly assigned to one of six lesioned groups or three sham-treated groups (Table 1): (1) mild lesioned $(5 \mu \mathrm{g})$ and no cast $(n=$ $8)$, (2) mild lesioned and contralateral cast on postoperative days 1-7 $(n=7)$, (3) severe lesioned $(10 \mu \mathrm{g} ; n=8)$, (4) severe lesioned and ipsilateral cast on postoperative days $1-7(n=7),(5)$ severe lesioned and ipsilateral cast on postoperative days 1-7 followed by contralateral cast on days 7-14 $(n=6)$, (6) severe lesioned and ipsilateral cast on postoperative days $1-7$ followed by contralateral cast on days $21-28(n=6),(7)$ sham and no cast $(n=6),(8)$ sham and ipsilateral cast $1-7(n=4)$, and (9) sham and ipsilateral cast on days 1-7 and contralateral cast on days 7-14 $(n=4)$. Cast groups were fitted with casts composed of plaster of Paris designed to immobilize the designated forelimb after surgery. Animals were allowed to recover to the point of moderate consciousness (determined by head orientation to whisker stimulation) before casting. The ipsilateral forelimb was placed in a naturally retracted position against the sternum, and strips of casting material were formed around the limb and upper torso (Jones and Schallert, 1994).

\section{Behavioral testing}

Limb use asymmetry (cylinder). Forelimb use during explorative activity was analyzed by videotaping rats in a transparent cylinder $(20 \mathrm{~cm}$ diameter and $30 \mathrm{~cm}$ height) for $5 \mathrm{~min}$ before lesioning and on days 14, 21 , 28, 35, and 40 after lesioning (Schallert and Tillerson, 2000; Tillerson et al., 2001). Wall exploration and landing scores were determined separately, and each were expressed in terms of (1) the percentage of use of the nonimpaired forelimb relative to the total number of limb use movements, (2) the percentage of use of the impaired forelimb relative to the total number of limb use movements, and (3) the percentage of co-use of both limbs (simultaneous or alternating) relative to the total number of limb use movements. The percentage of use of the impaired forelimb was then subtracted from the percentage of use of the nonimpaired forelimb for exploration and landing. These two scores (wall and landing) were averaged together for a single limb use asymmetry score that corrected for interanimal variability in the number of wall versus landing movements.

Forelimb akinesia. Movement initiation for each limb was assessed using the forelimb akinesia test (Schallert et al., 1992a,b; Lindner et al., 1997; Schallert and Tillerson, 2000; Tillerson et al., 2001). The hindquarters of the animal were suspended while the animal supported its weight on only one forelimb. The animal was allowed to initiate stepping movements in a $10 \mathrm{sec}$ period for one forelimb and then the other in a balanced order. Stepping measures for both limbs were recorded, and an ipsilateral asymmetry score was derived [(ipsilateral steps/ipsilateral + contralateral steps $)$ - (contralateral steps/ipsilateral + contralateral steps)]. If an animal struggled during testing, the data were not included in the overall analysis.

Forelimb placing deficit. A vibrissa-elicited forelimb-placing test was used (Schallert et al., 2000). Animals were held by their torsos, allowing forelimbs to hang free. Independent testing of each forelimb was induced by gently brushing the respective vibrissae on the edge of a tabletop once per trial for 10 trials. Intact animals place the forelimb of both sides quickly onto the counter top. Rats with unilateral 6-OHDA treatment show varying degrees of impaired limb-placing ability while still placing the unimpaired limb reliably. The percentage of unsuccessful placing responses was determined [(number placed contralaterally/number placed ipsilaterally) $\times 10$ ]. If an animal struggled during testing, the data were not included in the overall analysis.

Apomorphine-induced rotation. On day 18 after lesioning, the animals that received a high dose of 6-OHDA were given an injection of the DA receptor agonist apomorphine $(0.5 \mathrm{mg} / \mathrm{kg}$, s.c. $)$. Rats were then placed in a plastic bowl, and the number of rotations in a $20 \mathrm{~min}$ trial was recorded (Ungerstedt, 1971). Only animals given a $10 \mu \mathrm{g}$ dose of 6-OHDA were tested for apomorphine rotation.

\section{Neurochemical analyses}

Animals were anesthetized with carbon dioxide and decapitated $45 \mathrm{~d}$ after lesioning to permit neurochemical analyses. Two groups of measurements were made to assess the degree of terminal loss. First, DA and 

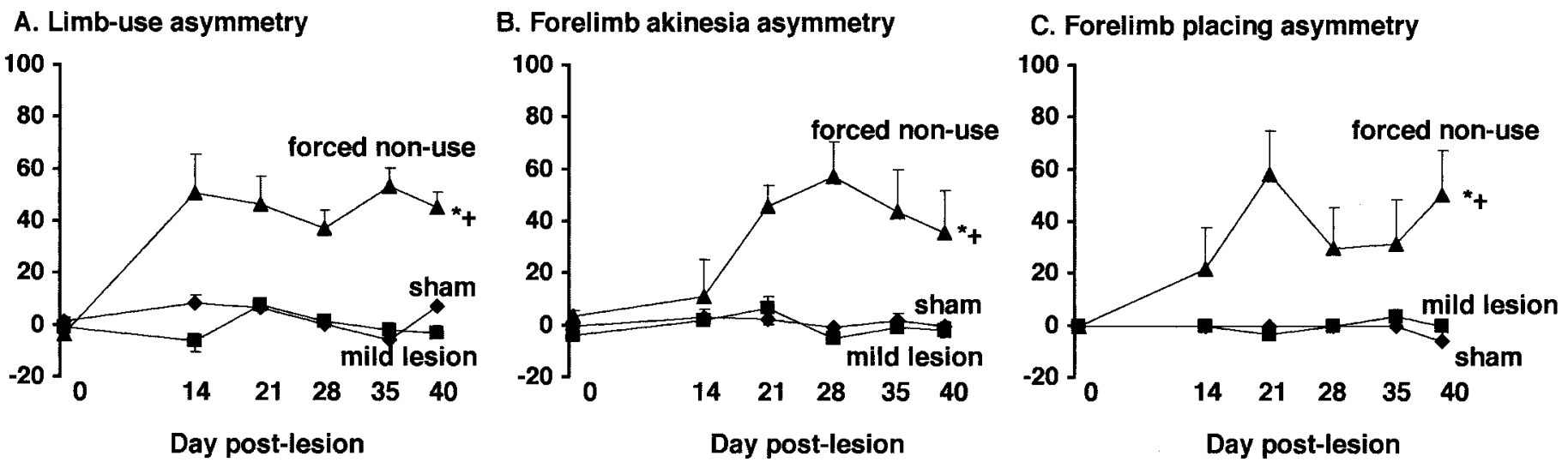

Figure 1. Behavioral asymmetries after forced nonuse in animals with mild lesions. A, Animals given mild unilateral lesions did not display significant limb use asymmetry. When animals were forced to not use the impaired forelimb for the first $7 \mathrm{~d}$ after lesioning, they demonstrated limb use asymmetry that persisted across testing days. $B$, Animals given mild unilateral lesions did not display significant forelimb akinesia. When animals were forced to not use the impaired forelimb for the first $7 \mathrm{~d}$ after lesioning, they demonstrated forelimb akinesia that persisted across testing days. $C$, Animals given mild unilateral lesions did suffer placing deficits. When animals were forced to not use the impaired forelimb for the first $7 \mathrm{~d}$ after lesioning, they demonstrated significant placing deficits that persisted across testing days $\left({ }^{*} p<0.01\right.$ compared with sham controls; ${ }^{+} p<0.01$ compared with lesion only).

its metabolites were measured by HPLC. Second, several proteins characteristic of DA terminals were measured by Western blot. These included the DA transporter (DAT), the VMAT2 present in the CNS, and tyrosine hydroxylase $(\mathrm{TH})$, the rate-limiting enzyme in DA biosynthesis.

\section{HPLC of striatal DA and metabolites}

A $1 \mathrm{~mm}$ section of the striatum (+1 $\mathrm{mm}$ to bregma) was dissected for both the ipsilateral and contralateral hemispheres. Dissected striata were assayed using minor modifications of previous methods. Tissue was sonicated in $0.1 \mathrm{M} \mathrm{HClO}_{2}$ perchloric acid containing $347 \mu \mathrm{M}$ sodium bisulfite and $134 \mu \mathrm{M}$ EDTA disodium salt. Homogenates were centrifuged at $16,000 \times g$ for $20 \mathrm{~min}$ at $4^{\circ} \mathrm{C}$, and the supernatant was removed. The supernatants were centrifuged at $16,000 \times g$ and were analyzed for levels of DA, 3,4-dihydroxyphenylacetic acid (DOPAC), and homovanillic acid (HVA) by HPLC (column, HR-80, $4.6 \mathrm{~mm} \times 8 \mathrm{~cm}$, four-channel coulometric electrode array; model 5600; ESA Inc., Chelmsford, MA) with sensitivity to femtomole levels). The mobile phase consisted of $16 \mathrm{~mm}$ citric acid monohydrate, $32 \mathrm{~mm}$ ammonium acetate, $215 \mu \mathrm{M}$ EDTA disodium salt, $850 \mu \mathrm{M}$ 1-octanesulfonic acid sodium salt monohydrate, final $\mathrm{pH} 2.5$, and $5 \%$ methanol (delivered at a constant flow rate of $1 \mathrm{ml} / \mathrm{min}$ ). Quantification was made by reference to calibration curves made with standards of DA hydrochloride (H8502; Sigma), DOPAC (D9128; Sigma) and HVA (H1252; Sigma).

\section{Western blot analysis of DAT, VMAT2, and TH}

DAT, VMAT2, and TH protein were measured to provide additional indices of striatal DA terminal integrity (Miller et al., 1997, 1999; Miller and Levey, 2001). Briefly, a $1 \mathrm{~mm}$ section of the striatum at the level of bregma was dissected from both the ipsilateral and contralateral hemispheres. Samples were homogenized in a buffer (in mM: 320 sucrose and 5 HEPES containing a protease inhibitor mixture). Homogenized samples were centrifuged at $2000 \times g$ for $5 \mathrm{~min}$, and the supernatant was centrifuged at $30,000 \times g$ for $30 \mathrm{~min}$. The final pellet was resuspended in homogenization buffer and subjected to PAGE (NuPage, 10\%; Invitrogen, San Diego, CA). Samples were electrophoretically transferred to a polyvinylidene difluoride membrane, and nonspecific sites were blocked in $7.5 \%$ nonfat dry milk in Tris-buffered saline $(135 \mathrm{~mm} \mathrm{NaCl}, 2.5 \mathrm{~mm}$ $\mathrm{KCl}, 50 \mathrm{~mm}$ Tris, and $0.1 \%$ Tween 20, $\mathrm{pH}$ 7.4). Membranes were then incubated in a polyclonal antibody to the $\mathrm{C}$ terminus of VMAT2 (VMAT2-Ct, AB1767; Chemicon, Temecula, CA) in Tris-buffered saline with $2 \%$ nonfat dry milk. VMAT2 antibody binding was detected using a goat anti-rabbit horseradish peroxidase secondary antibody (1706515; Bio-Rad, Hercules, CA) and enhanced chemiluminescence (CG50450; Pierce, Rockford, IL). The chemiluminescent signal was captured on an Alpha Innotech (San Leandro, CA) ChemiImager and stored as a digital image. Densitometric analysis was performed and calibrated to coblotted dilutional standards of control striata, and exposures performed within the linear range. Control striata for the standards were pooled from all noncasted sham animals. Membranes were then stripped for $20 \mathrm{~min}$ at $80^{\circ} \mathrm{C}(8 \mathrm{M}$ urea, $100 \mathrm{~mm}$ 2-mercaptoethanol, and $62.5 \mathrm{~mm}$ Tris, $\mathrm{pH}$ 6.8) and reprobed with a monoclonal antibody to the $\mathrm{N}$ terminus of DAT [rat anti-dopamine transporter antibody (Miller et al., 1997); MAB369; Chemicon; goat anti-rat secondary antibody, 56400; ICN, Costa Mesa, CA], a polyclonal TH antibody (rabbit anti-tyrosine hydroxylase, AB152; Chemicon), and $\alpha$-tubulin (T9026; Sigma) goat anti-mouse secondary antibody (170-6516; Bio-Rad).

\section{Statistical analysis}

Behavioral observations were first subjected to an overall repeated measures ANOVA. Post hoc analyses compared each lesion group with the collective sham group. Neurochemical measures were analyzed by applying a one-way ANOVA for group effect. Bonferroni post hoc comparisons of neurochemical data compared each treatment group. All post hoc measures were error-corrected to keep the overall error rate per group at 0.05. Statistical analyses were performed using SPSS (Chicago, IL) 10.0 software.

\section{RESULTS}

Mild 6-OHDA exposure: behavioral outcome after inactivity of the affected forelimb

Limb use asymmetry test

Casting of the impaired forelimb for the first $7 \mathrm{~d}$ after lesioning resulted in an exacerbation of behavioral asymmetry (Fig. 1A). As expected, immobilization of the forelimb in sham animals did not result in a significant behavioral difference between sham groups (no cast, ipsilateral cast on days 1-7, and ipsilateral cast on days $1-7 /$ contralateral cast on days $\left.7-14 ; F_{(2,11)}=0.182\right)$. Therefore, these three groups were pooled. Two-way ANOVA revealed a significant group-by-day interaction $\left(F_{(10,130)}=10.435 ; p<\right.$ 0.0001). A Dunnett post hoc analysis compared each lesion group with the pooled sham group. Animals given a unilateral $5 \mu \mathrm{g}$ inf usion of 6-OHDA were not different from intact animals in the limb use asymmetry task $(p=0.827)$. In contrast, animals forced to not use the impaired limb after surgery through day 7 displayed significant limb use asymmetry compared with both sham animals $(p<0.0001)$ and lesion-only animals $(p<0.0001)($ Fig. $1 A)$.

\section{Test for forelimb akinesia}

Casting the impaired forelimb during the first week after mild 6-OHDA insult resulted in significant long-term akinesia (Fig. 


\begin{tabular}{|c|c|c|c|c|c|c|}
\hline \multirow[b]{2}{*}{ Treatment } & \multicolumn{2}{|l|}{ DA } & \multicolumn{2}{|l|}{ DOPAC } & \multicolumn{2}{|l|}{ HVA } \\
\hline & Lesion & Control & Lesion & Control & Lesion & Control \\
\hline Sham & $\begin{array}{c}4307.842 \\
(138.558)\end{array}$ & $\begin{array}{l}3961.819 \\
(184.292)\end{array}$ & $\begin{array}{l}1837.953 \\
(282.862)\end{array}$ & $\begin{array}{l}1823.590 \\
(239.094)\end{array}$ & $\begin{array}{c}744.642 \\
(282.862)\end{array}$ & $\begin{array}{c}844.240 \\
(282.862)\end{array}$ \\
\hline Mild & $\begin{array}{l}4750.992 \\
(702.295)\end{array}$ & $\begin{array}{c}5656.939 \\
(1040.050)\end{array}$ & $\begin{array}{c}970.742 \\
(131.125)\end{array}$ & $\begin{array}{l}1151.906 \\
(119.763)\end{array}$ & $\begin{array}{c}494.548 \\
(85.275)\end{array}$ & $\begin{array}{c}548.449 \\
(110.900)\end{array}$ \\
\hline Mild disuse & $\begin{array}{c}2454.705^{*} \\
(568.491)\end{array}$ & $\begin{array}{l}5788.365 \\
(502.167)\end{array}$ & $\begin{array}{c}864.096^{*} \\
(280.316)\end{array}$ & $\begin{array}{l}1953.835 \\
(529.942)\end{array}$ & $\begin{array}{c}234.196^{*} \\
(49.820)\end{array}$ & $\begin{array}{l}1021.860 \\
(193.834)\end{array}$ \\
\hline Severe & $\begin{array}{c}332.313^{*} \\
(166.243)\end{array}$ & $\begin{array}{c}3705.452 \\
(759.202)\end{array}$ & $\begin{array}{l}1138.351 \\
(485.891)\end{array}$ & $\begin{array}{c}2821.755 \\
(522.180)\end{array}$ & $\begin{array}{c}276.384 \\
(67.360)\end{array}$ & $\begin{array}{c}960.182 \\
(236.942)\end{array}$ \\
\hline Severe forced use & $\begin{array}{c}2770.143^{*} \\
(424.296)\end{array}$ & $\begin{array}{l}2921.686 \\
(360.341)\end{array}$ & $\begin{array}{c}2754.516 \\
(513.147)\end{array}$ & $\begin{array}{l}1848.543 \\
(283.544)\end{array}$ & $\begin{array}{c}663.194 \\
(60.629)\end{array}$ & $\begin{array}{c}559.709 \\
(46.324)\end{array}$ \\
\hline Severe forced use $1-7 /$ nonuse $7-14$ & $\begin{array}{c}2454.705^{*} \\
(568.491)\end{array}$ & $\begin{array}{l}5788.365 \\
(502.167)\end{array}$ & $\begin{array}{c}864.096 \\
(280.316)\end{array}$ & $\begin{array}{l}1953.835 \\
(529.942)\end{array}$ & $\begin{array}{c}234.196 \\
(49.820)\end{array}$ & $\begin{array}{l}1021.860 \\
(193.834)\end{array}$ \\
\hline Severe forced use $1-7 /$ nonuse $21-28$ & $\begin{array}{l}1247.870^{*} \\
(643.967)\end{array}$ & $\begin{array}{l}3630.127 \\
(959.965)\end{array}$ & $\begin{array}{l}1112.905 \\
(557.069)\end{array}$ & $\begin{array}{l}2662.631 \\
(564.272)\end{array}$ & $\begin{array}{c}492.656 \\
(144.289)\end{array}$ & $\begin{array}{c}787.380 \\
(111.021)\end{array}$ \\
\hline
\end{tabular}

*Significantly different from sham group. $p<0.05$. No significant differences were found in the nonlesion hemispheres.

1B). There were no significant differences among the three sham groups on akinetic scores, and these three groups were pooled for further analysis $\left(F_{(2,10)}=0.259\right)$. An overall two-way ANOVA revealed a significant group-by-day interaction $\left(F_{(10,110)}=3.584\right.$; $p<0.001)$. As in the limb use asymmetry analysis, primary interest lay in comparing each group to the pooled sham group. Post hoc analyses again revealed that in contrast to mild lesion animals and sham controls, animals forced to not use the impaired limb during the time of degeneration showed significant akinesia $(p<0.0001)$ (Fig. 1B).

\section{Forelimb placing}

Casting the impaired forelimb during the first week after lesioning resulted in significant placing deficits (Fig. 1C). As with the other analyses, sham groups were pooled because statistical analysis indicated that they did not differ $\left(F_{(2,10)}=1.059\right)$. An overall two-way ANOVA revealed a significant group-by-day interaction $\left(F_{(10,110)}=3.880 ; p<0.001\right)$. Unlike lesioned animals that were not casted and sham controls, animals forced to not use the impaired limb for the first $7 \mathrm{~d}$ after insult displayed significant placing deficits $(p<0.0001)$ (Fig. 1C).

\section{Mild 6-OHDA exposure: neurochemical loss after inactivity of the affected forelimb}

Percentage of $\mathrm{DA}$ remaining in the lesioned striatum

The percentages of DA, DOPAC, and HVA remaining in the lesioned hemisphere were calculated by dividing the amount of each compound in the striatum of the lesioned hemisphere by the content of the striatum in the nonlesioned hemisphere. No significant differences were found in DA, DOPAC, or HVA measures in the nonlesioned hemisphere (for mean levels, see Table $2)$. In addition, no significant differences were found between sham groups $\left(\mathrm{DA}, F_{(2,11)}=1.549 ;\right.$ DOPAC, $F_{(2,11)}=0.613$; $\left.\mathrm{HVA}, F_{(2,11)}=0.719\right)$; therefore, these three groups were combined. A one-way ANOVA indicated a significant group effect for DA content and its metabolites (DA, $F_{(2,26)}=37.080 ; p<0.0001$; DOPAC, $F_{(2,26)}=7.969 ; p<0.01$; HVA, $F_{(2,26)}=36.131 ; p<$ 0.0001). Post hoc analysis revealed that DA levels were significantly decreased in the animals that received lesions but no casts when compared with sham $(p<0.05)$ (Fig. $2 A)$.
Further analysis showed that whereas there were significant declines in DA, DOPAC, and HVA levels in lesioned and casted animals compared with sham animals (DA, $p<0.0001$; DOPAC, $p<0.01$; HVA, $p<0.001)$, these animals had significantly greater reductions in DA $(p<0.0001)$ and HVA $(p<0.001)$ when compared with animals that were lesioned but not casted. No significant differences in DOPAC/DA ratios were found between groups $\left(F_{(2,26)}=1.604\right)$. Therefore, forced nonuse of the impaired limb not only led to significant behavioral impairments but also resulted in exacerbation of striatal DA loss.

\section{Changes in striatal DA terminal proteins}

The percentages of DAT, VMAT2, and $\mathrm{TH}$ remaining in the lesioned hemisphere were calculated by dividing the level in the striatum of the lesioned hemisphere by the level of the striatum in the nonlesioned hemisphere (for mean levels, see Table 3). No significant differences were found between sham groups (DAT, $\left.F_{(2,10)}=0.860 ; \mathrm{VMAT} 2, F_{(2,10)}=0.098 ; \mathrm{TH}, F_{(2,10)}=0.912\right)$; therefore, these groups were combined for further analyses.

Significant losses in DAT $\left(F_{(2,22)}=12.804 ; p<0.0001\right)$ were found between treatment groups. Post hoc analysis found a significant decline in reactivity in animals forced to not use the impaired limb when compared with both sham animals $(p<$ $0.0001)$ and lesion-only animals $(p<0.02)$. A significant overall group effect was seen in VMAT2 levels $\left(F_{(2,22)}=14.482 ; p<\right.$ $0.0001)$. The characteristic three immunoreactive VMAT2 bands were observed at 75, 55, and $45 \mathrm{kDa}$. The $75 \mathrm{kDa}$ (glycosylated), active VMAT2 band was quantified (Miller et al., 1999). Post hoc analysis revealed a significant loss for animals forced to not use the impaired limb when compared with both sham $(p<0.0001)$ and lesion-only $(p<0.01)$ groups. Finally, a significant overall group effect was seen in TH immunoreactivity $\left(F_{(2,22)}=10.497\right.$; $p<0.01)$. As with DAT and VMAT2, animals forced to not use the impaired forelimb had significantly less reactivity compared with sham $(p<0.01)$ and lesion-only $(p<0.01)$ groups (Fig. $2 B, C)$. Tubulin blots indicated equal loading of samples across treatment groups (data not shown). 
A.

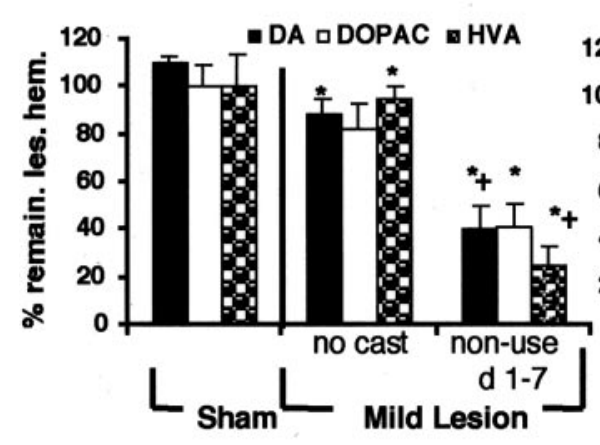

B.

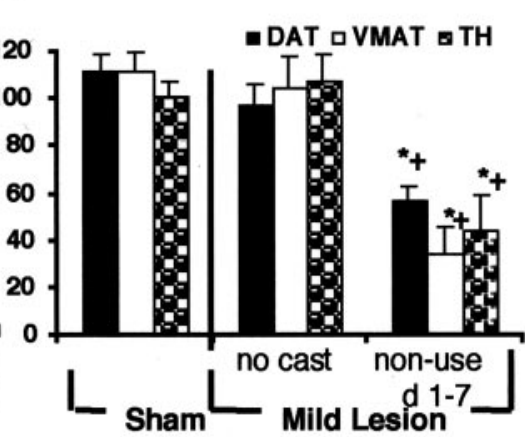

C.

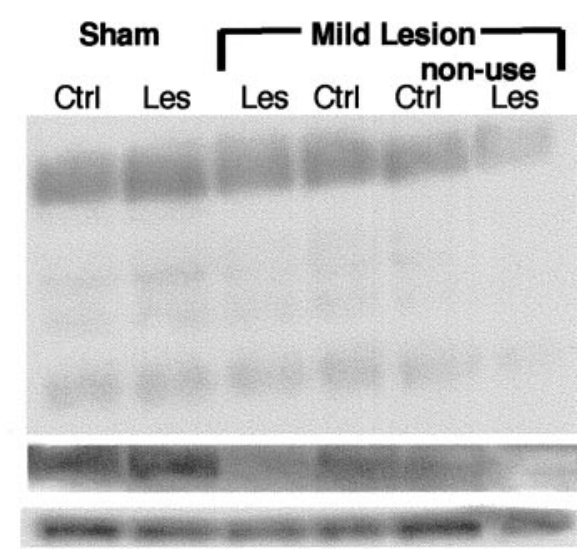

Figure 2. Effect of forced nonuse of the impaired forelimb after mild 6-OHDA lesion. $A$, A $5 \mu \mathrm{g}$ inf usion of 6-OHDA resulted in only a mild loss of DA and HVA in striatal tissue when values were compared with the intact hemisphere. In contrast, forced nonuse of the impaired forelimb for the first $7 \mathrm{~d}$ after lesioning resulted in significantly greater loss of DA and its metabolites when compared with both sham animals and animals lesioned but not casted; ${ }^{*} p<0.05$ compared with sham; ${ }^{+} p<0.01$ compared with lesion/no cast. $B$, Immunoreactivity of DAT, VMAT2, and TH was not reduced after mild lesioning (calculated as percentage remaining in lesion hemisphere). In contrast, forced nonuse of the impaired forelimb for the first $7 \mathrm{~d}$ after lesioning resulted in significant declines in DAT, VMAT2, and TH immunoreactivity; ${ }^{*} p<0.01$ compared with sham; ${ }^{+} p<0.02$ compared with lesion/no cast. $C$, Representative blots of VMAT2, DAT, and TH for sham, mild lesion, and mild lesion and nonuse groups. Ctrl, Control; Les, lesion.

Table 3. Immunoreactivity of DA terminal markers in treatment groups

\begin{tabular}{|c|c|c|c|c|c|c|}
\hline \multirow[b]{2}{*}{ Treatment } & \multicolumn{2}{|l|}{ DAT } & \multicolumn{2}{|c|}{$\underline{\text { VMAT2 }}$} & \multicolumn{2}{|l|}{$\mathrm{TH}$} \\
\hline & Lesion & Control & Lesion & Control & Lesion & Control \\
\hline \multirow[t]{2}{*}{ Sham } & 29.442 & 27.557 & 27.155 & 24.821 & 22.695 & 22.962 \\
\hline & $(1.244)$ & $(1.292)$ & $(2.770)$ & $(2.320)$ & $(1.750)$ & $(2.147)$ \\
\hline \multirow[t]{2}{*}{ Mild } & 32.133 & 34.070 & 32.093 & 33.946 & 23.88 & 22.35 \\
\hline & $(0.179)$ & $(2.567)$ & $(2.084)$ & $(5.245)$ & $(2.257)$ & $(0.892)$ \\
\hline \multirow[t]{2}{*}{ Mild disuse } & $17.399^{*}$ & 30.553 & $8.349^{*}$ & 27.495 & 12.135 & 23.670 \\
\hline & $(2.127)$ & $(0.386)$ & $(2.476)$ & $(2.143)$ & $(4.181)$ & $(2.233)$ \\
\hline \multirow[t]{2}{*}{ Severe } & $3.147^{*}$ & 13.668 & $1.425^{*}$ & 12.357 & $4.12^{*}$ & 16.187 \\
\hline & $(1.331)$ & (3.111) & $(0.968)$ & $(2.648)$ & (1.118) & $(3.364)$ \\
\hline \multirow[t]{2}{*}{ Severe forced use } & 11.248 & 17.151 & 14.401 & 19.841 & 18.846 & 24.473 \\
\hline & $(2.572)$ & $(1.880)$ & $(1.077)$ & $(2.180)$ & $(2.713)$ & $(3.988)$ \\
\hline \multirow[t]{2}{*}{ Severe forced use $1-7 /$ nonuse $7-14$} & 12.378 & 22.608 & $8.321^{*}$ & 14.406 & 11.504 & 24.782 \\
\hline & $(4.395)$ & $(5.448)$ & $(2.367)$ & $(2.605)$ & $(2.703)$ & $(4.465)$ \\
\hline \multirow[t]{2}{*}{ Severe forced use $1-7 /$ nonuse $21-28$} & 10.091 & 18.948 & $4.585^{*}$ & 10.985 & $6.905^{*}$ & 17.011 \\
\hline & $(3.761)$ & $(4.475)$ & $(2.820)$ & $(2.766)$ & $(2.898)$ & $(1.355)$ \\
\hline
\end{tabular}

*Significantly different from sham group. $p<0.05$.

Severe 6-OHDA exposure: behavioral effects of delayed nonuse of the impaired forelimb in animals previously recovered from severe dopaminergic lesion

Limb use asymmetry test

Seven days of forced nonuse of the impaired forelimb beginning 7 or $21 \mathrm{~d}$ after behavioral recovery resulted in a reinstatement of lesion-induced behavioral asymmetry (Fig. 3A). Two-way ANOVA revealed a significant group-by-day interaction $\left(F_{(20,190)}=9.5 ; p<\right.$ 0.0001). Post hoc analysis compared each lesion group with the pooled sham group. Animals that received a severe unilateral lesion demonstrated significant behavioral asymmetry that persisted across testing days compared with sham animals $(p<$ 0.0001). As demonstrated previously (Tillerson et al., 2001), forced reliance of the impaired forelimb for the first $7 \mathrm{~d}$ after a severe unilateral 6-OHDA lesion abolished this asymmetry ( $p=$ 0.731) (Fig. 3A). However, when animals forced to rely on the impaired limb for $7 \mathrm{~d}$ after injury were later forced to not use the impaired limb, a reinstatement of behavioral asymmetry was observed (forced use during days $1-7$, followed by nonuse on days $14-21, p<0.001$; forced use during days $1-7$ followed by nonuse on days $21-28, p<0.0001)$.

\section{Test for forelimb akinesia}

Animals that had shown the ameliorative effects of $7 \mathrm{~d}$ of forced use of their impaired limb were then subjected to a cast on that limb for $7 \mathrm{~d}$ beginning on postoperative day 7 or 21 . Such forcing of inactivity of the impaired forelimb resulted in a reinstatement of lesion-induced akinesia (Fig. 3B). Two-way ANOVA revealed a significant group-by-day interaction $\left(F_{(20,175)}=9.323 ; p<\right.$ 0.0001). Post hoc analysis reflected severe forelimb akinesia in animals that received a severe unilateral lesion compared with sham animals $(p<0.0001)$.

No difference was observed between animals forced to rely on their impaired limb for the first $7 \mathrm{~d}$ after lesioning compared with sham control animals $(p=0.888)$, a finding consistent with our previous demonstration (Tillerson et al., 2001). However, when 
A. Limb-use asymmetry

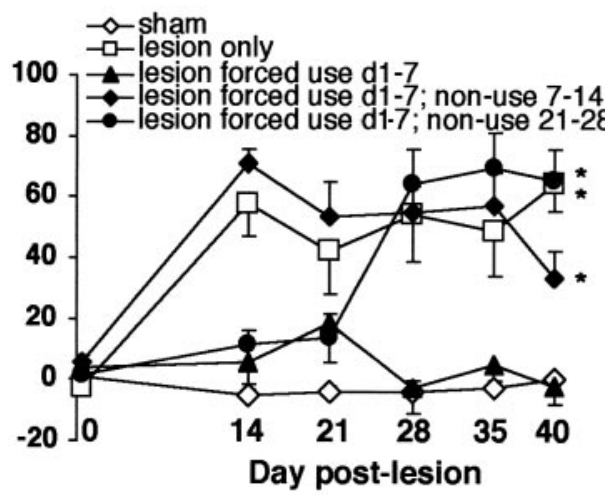

B. Forelimb akinesia asymmetry

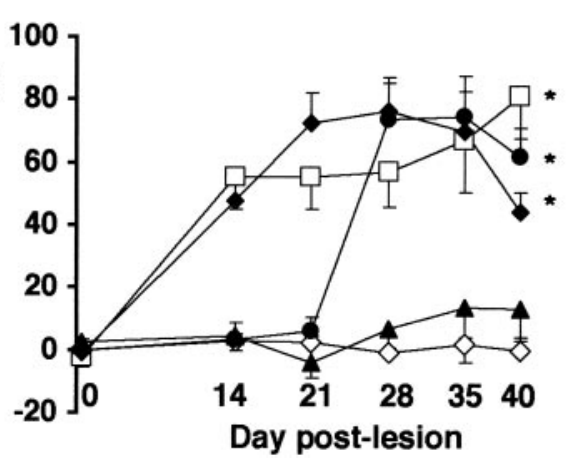

\section{Forelimb placing asymmetry}

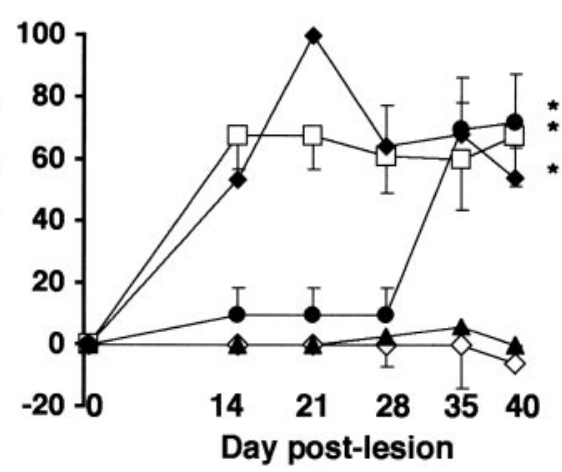

Figure 3. Behavioral asymmetries after forced nonuse in animals with severe DA lesions. A, Animals forced to rely on the impaired forelimb for the first $7 \mathrm{~d}$ after severe unilateral lesioning did not display characteristic limb use asymmetry. In contrast, when animals were later forced to not use the impaired forelimb after recovery induced by forced use, asymmetrical limb use characteristic of the high dose of 6-OHDA received at the time of surgery was observed $\left({ }^{*} p<0.01\right)$. B, Animals forced to rely on the impaired forelimb for the first $7 \mathrm{~d}$ after severe unilateral lesioning did not display characteristic forelimb akinesia. In contrast, when animals were later forced to not use the impaired forelimb after recovery induced by forced use, marked forelimb akinesia characteristic of the amount of neurotoxin sustained during surgery was observed $\left({ }^{*} p<0.01\right)$. $C$, Animals forced to rely on the impaired forelimb for the first $7 \mathrm{~d}$ after severe unilateral lesioning did not display characteristic placing deficits. In contrast, when animals were later forced to not use the impaired forelimb after forced use-induced recovery, occurrence or reinstatement of placing inability was observed $\left({ }^{*} p<0.01\right)$.

animals forced to rely on the impaired limb for $7 \mathrm{~d}$ after injury had their recovered forelimb restrained, a reinstatement of behavioral asymmetry was observed (forced use on days 1-7 followed by nonuse on days $14-21, p<0.0001$; forced use on days $1-7$ followed by nonuse on days $21-28, p<0.0001$ ) (Fig. $3 B$ ).

\section{Forelimb placing}

Forcing nonuse of the impaired forelimb on days 7-14 or 21-28 after forced use-induced behavioral recovery resulted in a reinstatement of lesion-induced placing deficits (Fig. 3C). Two-way ANOVA revealed a significant group-by-day interaction $\left(F_{(20,175)}\right.$ $=7.650 ; p<0.0001)$. Post hoc analysis reflected a significant placing deficit in animals that received a severe unilateral lesion compared with sham animals $(p<0.0001)$. In contrast, forced reliance of the impaired forelimb for the first $7 \mathrm{~d}$ after a severe unilateral 6-OHDA lesion resulted in amelioration of the placing deficit $(p=0.990)$. When animals forced to rely on the impaired limb for $7 \mathrm{~d}$ after injury were later forced to not use that limb, a reinstatement of the deficit typically associated with this high dose of 6-OHDA was observed (forced use on days 1-7 followed by nonuse on days 14-21, $p<0.0001$; forced use on days 1-7 followed by nonuse on days $21-28, p<0.001$ ) (Fig. 3C).

\section{Apomorphine rotation}

A subset of animals in the sham and severe lesion groups were tested for apomorphine rotation on day 18 after lesioning. In addition, animals casted to promote forced use on days 1-7 and then exposed to nonuse on days 21-28 were tested on day 35 after lesioning. An overall significant group effect was found in apomorphine-induced contralateral rotation $\left(F_{(5,31)}=12.294 ; p<\right.$ 0.0001) (Fig. 4A,B). Post hoc analysis revealed significantly higher rotation in the lesion-only group compared with shams $(p<0.05)$. Animals forced to rely on the impaired forelimb for the first $7 \mathrm{~d}$ after lesioning did not display significant rotation $(p=1.0)$. In contrast, forced reliance on the impaired limb on days 1-7 after lesioning followed by forced nonuse of the limb on days 7-14 yielded severe apomorphine rotation $(p<0.05)$. When animals forced to use their impaired limb on days $1-7$ and subsequently forced to not use that limb on days 21-28 were tested before the

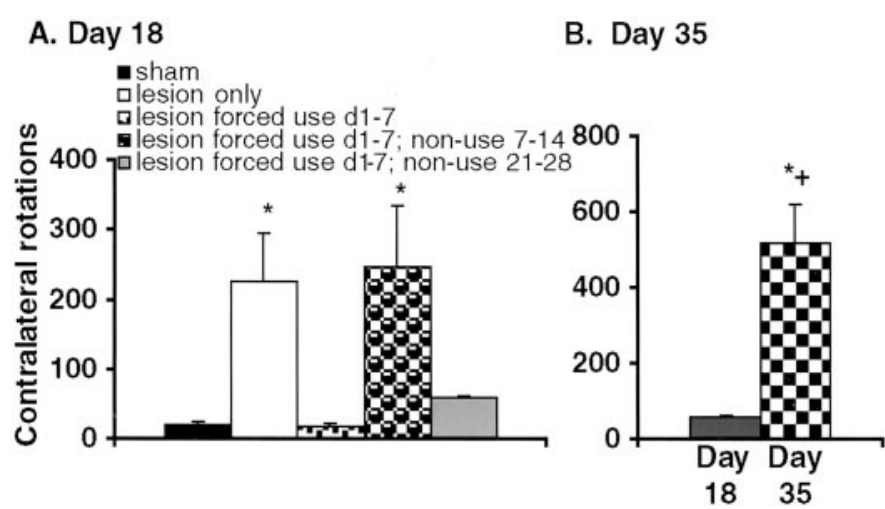

Figure 4. Apomorphine-induced rotation after forced nonuse in animals with recovery of function. $A$, Unilateral $10 \mu \mathrm{g}$ infusion of 6-OHDA resulted in significant contralateral rotation after apomorphine administration $18 \mathrm{~d}$ after lesioning. Forced use of the impaired forelimb for the first $7 \mathrm{~d}$ after lesioning resulted in an absence of apomorphine-induced rotation. When animals were forced to not use the limb on days 7-14 after a $7 \mathrm{~d}$ period of forced use, they displayed significant apomorphine rotation. $B$, Animals forced to rely on the impaired forelimb for the first $7 \mathrm{~d}$ after lesioning and later had the impaired forelimb casted on days 21-28 did not display significant apomorphine-induced rotation $18 \mathrm{~d}$ after lesioning. In contrast, when tested on day 35 after lesioning (after the period of nonuse), these animals displayed significant contralateral rotation $\left({ }^{*} p<0.05\right.$ compared with shams; ${ }^{+} p<0.01$ day 18$)$.

second cast (day 18 after lesioning), they did not display significant rotation $(p=1.0)$. However, when these animals were again tested after the forced inactivity of the lesion-affected forelimb (on day 35 after lesioning), strong contralateral rotation was measured (forced use on days 1-7 and nonuse on days 21-28 tested on day 35 vs sham, $p<0.0001$; vs tested on day $18, p<0.0001$ ).

\section{Severe 6-OHDA exposure: neurochemical loss after delayed nonuse in animals previously recovered from severe DA lesion}

Percentage of DA remaining in the lesioned striatum

The percentages of DA, DOPAC, and HVA remaining in the lesioned hemisphere was calculated by dividing the amount of 


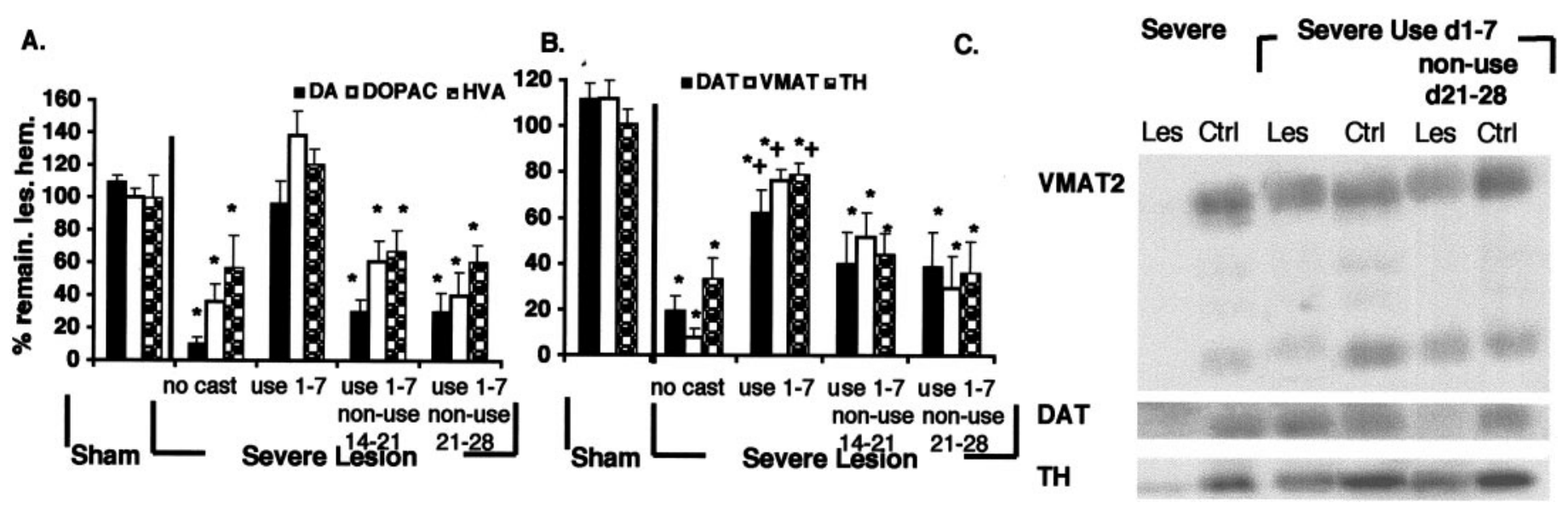

Figure 5. Effect of forced nonuse of the impaired forelimb after severe 6-OHDA lesion. $A$, A $10 \mu \mathrm{g}$ inf usion of 6-OHDA resulted in severe lesioning as reflected by significant decrease in the percentage of DA, DOPAC, and HVA remaining. Forced use of the impaired forelimb for the first $7 \mathrm{~d}$ after lesioning resulted in amelioration of these losses, but subsequent nonuse of the impaired forelimb on days 7-14 or 21-28 resulted in a reinstatement of lesion induced losses; ${ }^{*} p<0.01$ compared with sham. $B$, Immunoreactivity of DAT, VMAT2, and TH was significantly reduced after a $10 \mu \mathrm{g}$ unilateral lesion, but the reactivity of these proteins was significantly increased after forced use of the impaired forelimb for the first $7 \mathrm{~d}$ after lesioning. A subsequent period of nonuse after forced use resulted in decreased immunoreactivity of DAT, VMAT2, and TH $\left({ }^{*} p<0.01\right.$ sham; ${ }^{+} p<0.01$ lesion only). $C$, Representative blots of VMAT2, DAT, and TH for animals subjected to a severe lesion only, severe lesion plus forced use on postoperative days 1-7, and severe lesion plus forced use on days 1-7 followed by nonuse on days 21-28. Ctrl, Control; Les, lesion.

each compound in the striatum of the lesioned hemisphere by the content of the striatum in the nonlesioned hemisphere (for mean levels, see Table 2).

When animals were forced to rely on the impaired forelimb for the first $7 \mathrm{~d}$ after a $10 \mu \mathrm{g}$ infusion of 6-OHDA, and then the cast was removed to allow normal activity in both limbs, an attenuation of striatal DA loss was measured on day 45 after lesioning (Fig. $5 A$ ). In contrast, in animals that were forced to rely on the impaired forelimb for the first $7 \mathrm{~d}$ after injury followed by forced inactivity of the impaired forelimb, either on days 7-14 or 21-28, no sparing of DA measures was found in the striatum on day 45 after lesioning (Fig. 5A). One-way ANOVA indicated a significant group effect for DA content and its metabolites $\left(\mathrm{DA}, F_{(4,35)}=\right.$ 41.283; $p<0.0001$; DOPAC, $F_{(4,35)}=11.738 ; p<0.001$; HVA, $\left.F_{(4,35)}=8.565 ; p<0.001\right)$. Post hoc analysis revealed that DA $(p<0.001)$, DOPAC $(p<0.01)$, and HVA $(p<0.001)$ levels were significantly declined in the severe lesion-only group compared with sham animals. In contrast, animals forced to rely on the impaired limb for the first $7 \mathrm{~d}$ after lesioning did not differ in the extent of their DA loss $(p=0.537)$, DOPAC $(p=0.076)$, and HVA $(p=0.951)$ compared with sham animals. When animals forced to rely on the impaired limb for the first $7 \mathrm{~d}$ after lesioning were later forced to not use the impaired limb, significant losses in DA (forced use on days 1-7 followed by nonuse on days 7-14, $p<0.001$; forced use on days 1-7 followed by nonuse on days $21-28, p<0.01$ ), DOPAC (forced use on days $1-7$ followed by nonuse on days $7-14$ or $21-28, p<0.01$ ), and HVA (forced use on days $1-7$ followed by nonuse on days $7-14$ or $21-28, p<0.01$ ) were measured. A significant overall effect in DOPAC/DA ratios was also measured $\left(F_{(4,35)}=6.408 ; p=0.001\right)$. Significant increases in this ratio were measured in lesioned animals that were not casted $(p<0.01)$ and in lesioned animals subjected to forced use on days 1-7 and then forced to not use the limb on days 21-28 $(p<0.01)$ compared with sham controls. Thus, forced nonuse of the impaired forelimb after a period of forced use-induced recovery yielded a lesion-induced striatal DA content and metabolite loss that was consistent with that expected by the high level of neurotoxin endured at the time of surgery.

\section{Western blot}

The percentages of DAT, VMAT2, and $\mathrm{TH}$ remaining in the lesioned hemisphere were calculated by dividing the level in the striatum of the lesioned hemisphere by the level in the nonlesioned hemisphere (for mean levels, see Table 3).

Significant losses in DAT $\left(F_{(4,35)}=17.744 ; p<0.0001\right)$ were found between treatment groups (Fig. 5B,C). Post hoc analysis found a significant decline in reactivity in lesion-only animals $(p<0.001)$. Animals forced to rely on the impaired limb for the first $7 \mathrm{~d}$ after lesioning also displayed decreased immunoreactivity when compared with sham controls $(p<0.01)$ (Fig. 5B). However, these animals also displayed a significant increase in DAT reactivity when compared with lesion-only groups $(p<$ $0.05)$, reflecting the neurochemical improvement after forced reliance on the impaired forelimb. Animals forced to rely on the impaired limb for the first $7 \mathrm{~d}$ after lesioning and then subjected to nonuse of the same limb on days 7-14 had significant declines in DAT reactivity compared with shams $(p<0.001)$, as did animals in the group with forced use on days 1-7 followed by nonuse on days 21-28 ( $p<0.001)$ (Fig. 5B).

A significant overall group effect was seen in VMAT2 levels $\left(F_{(4,35)}=29.859 ; p<0.0001\right)$ (Fig. 5B,C). Post hoc analysis found a significant decline in reactivity in lesion-only animals $(p<$ 0.001). In addition, animals forced to rely on the impaired limb for the first $7 \mathrm{~d}$ after lesioning also displayed decreased immunoreactivity when compared with sham controls $(p<0.02)$. However, these animals also displayed a significant increase in VMAT2 reactivity when compared with lesion-only groups $(p<$ $0.001)$, reflecting the neurochemical improvement after forced reliance on the impaired forelimb (Fig. 5B). Animals forced to rely on the impaired limb for the first $7 \mathrm{~d}$ after lesioning but then subject to nonuse of that limb on days $7-14$ had significant declines in VMAT2 reactivity compared with shams $(p<0.001)$, as did animals in the group with forced use on days 1-7 followed by nonuse on days $21-28(p<0.001)$ (Fig. $5 B)$.

Finally, a significant overall group effect was seen in TH immunoreactivity $\left(F_{(4,35)}=14.754 ; p<0.0001\right)($ Fig. $5 B, C)$. As with 
DAT and VMAT2, lesion-only animals had significantly less reactivity compared with sham animals $(p<0.0001)$, as did animals that were lesioned, forced to use their impaired limb on days $1-7$, and then had that limb casted on days 7-14 $(p<0.0001)$ or on days 21-28 ( $p<0.001)$ (Fig. 5B). Animals forced to rely on the impaired forelimb for the first $7 \mathrm{~d}$ after injury only also had decreased $\mathrm{TH}$ reactivity compared with sham controls but did display significantly more $\mathrm{TH}$ reactivity compared with animals that were lesioned but not casted, again reflecting the induced striatal neuroplasticity after forced use of the impaired forelimb alone (Fig. 5B,C). Tubulin blots indicated equal loading of samples across treatment groups (data not shown).

\section{DISCUSSION}

An overall decrease in physical activity is an early feature of PD, occurring years before the first appearance of diagnostic symptoms (Fertl et al., 1993; Comella et al., 1994; Toth et al., 1997; Mazzoni and Ford, 1999). Indeed, this decline in activity is reflected in animal models of the disease (Schallert and Hall, 1988; Lees, 1992; Schallert and Tillerson, 2000). On the other hand, increased physical activity has been found to improve motor ability and to increase life span in patients in the latter stages of their disease (Bilowit, 1956; Knott, 1957; Franklyn et al., 1981; Szekely et al., 1982; Palmer et al., 1986; Hurwitz, 1989; Toole et al., 2000). In addition, recent studies have demonstrated the positive effects of forced movement in a variety of animal models of CNS injury (Jones and Schallert, 1994; Stroemer et al., 1995; Bury et al., 2000; Carro et al., 2001; Tillerson et al., 2001). For example, we have shown recently that forced reliance on the impaired forelimb for the first $7 \mathrm{~d}$ after unilateral 6-OHDA insult resulted in decreased striatal DA loss and recovery from behavioral asymmetries (Tillerson et al., 2001). This combination of findings relating physical activity to symptoms in animal models and PD patients led us to hypothesize that decreased physical activity may not only be a symptom of dopaminergic damage but may also contribute to the disease process.

In this study, we first examined the effects of forced restraint of the impaired forelimb in animals with mild unilateral 6-OHDA lesions. Forced nonuse of the impaired forelimb for the first $7 \mathrm{~d}$ after lesioning resulted in long-term behavioral impairments and exacerbation of neurochemical damage. Sensitive behavioral measures that have been shown previously to be significantly correlated with striatal DA content (Schallert and Tillerson, 2000; Tillerson et al., 2001) were performed up to day 40 after lesioning. Uncasted animals given mild DA-depleting lesions did not display detectable behavioral impairments on any of the tests, a result consistent with previous findings with such DA lesions. However, animals given the same mild dose of 6-OHDA along with restraint of the impaired forelimb for the first $7 \mathrm{~d}$ after lesioning displayed significant behavioral deficits that persisted across testing days (Fig. 1). In addition to increased behavioral impairments, evaluation of the nigrostriatal system by HPLC analysis and Western blot analysis for DAT, VMAT2, and TH indicated significant increases in the loss of DA terminals in animals forced to not use the impaired forelimb during the first $7 \mathrm{~d}$ after lesioning (Fig. 2).

We also tested the effects of forced nonuse after the protective effects of forced use in rats exposed to a larger dose of 6-OHDA. As demonstrated previously (Tillerson et al., 2001), we found that forced use of the impaired forelimb for the first $7 \mathrm{~d}$ after insult resulted in behavioral sparing (Figs. 3, 4) and increased striatal DA levels (Fig. 5A). DAT, VMAT2, and TH immunoreactivity was also significantly increased, although we did detect a decline in DAT reactivity compared with sham control (Fig. $5 B$ ). In contrast, marked behavioral deficits (Figs. 3, 4) and neurochemical deficits (Fig. 5) were observed in animals first subjected to the protective effects of forced use followed by delayed forced inactivity of the forelimb corresponding to the lesioned hemisphere.

In both sets of experiments, forced inactivity of the forelimb corresponding to the lesion resulted in marked behavioral and neurochemical loss. Animals given mild lesions to the nigrostriatal system did not display behavioral asymmetry and thus maintained use of the impaired forelimb after injury. Postinjury use was the only factor changed in these experiments, and this strongly suggests that the compensatory mechanisms that allow for near-normal striatal DA content and behavioral symmetry are use-dependent. Physical activity alone promotes several factors that may modify the impact of injury, such as growth factor production (Neeper et al., 1995; Gomez-Pinilla et al., 1997, 1998; Widenfalk et al., 1999; Bury et al., 2000; Carro et al., 2001), alterations in neurotransmitter synthesis and transmission (Meeusen and De Meirleir, 1995), and neurogenesis (Czurko et al., 1999; van Praag et al., 1999). Indeed, forced use of a forelimb in sham-operated animals increases FGF-2, glial cell-line derived neurotrophic factor, and BDNF expression (Cohen et al., 2001; Stewart et al., 2001). In addition, acrobat training after minor denervation paired with behavioral demand results in trophic factors and neuronal morphological changes related to synaptogenesis (Bury et al., 2000). Therefore, possible mechanisms underlying the results found in these experiments include a decline in any of these and other activity-dependent changes. An improved understanding of potential mechanisms of activitydependent events will lend further insight into these phenomena and may aid in the development of treatments for PD patients.

It is important to note that the effects of physical activity and inactivity demonstrated in this paper may derive not only from an influence on the nigrostriatal neurons but also from an influence on associated nondopaminergic neurons. Use-dependent changes in nondopaminergic neurons may be essential, including intrinsic neurons of the striatum and associated regions. For example, motor behavior affects corticostriatal glutamatergic projections and GABAergic medium spiny neurons. If the status of nondopaminergic target cells were markedly altered by sensorimotor experience soon after neurotoxin exposure, it is reasonable that this could have a major impact on the degree to which nigrostriatal terminals maintain or regain the connections.

Finally, it is possible that animals forced to not use the forelimb corresponding to the lesioned hemisphere were subjected to more 6-OHDA. This might occur, for example, if forced nonuse resulted in a decrease in the activity of DA neurons and a subsequent increase in the amount of toxin taken up by the contralateral DA neurons. However, although there is some evidence for an activity-dependent regulation of DAT (Sharpe et al., 1991; Wilson et al., 1996a,b), it seems unlikely that the interactions reported thus far would account for the rather profound effects of forced inactivity that we have reported here.

The positive effects of forced use in unilateral 6-OHDAtreated rats replicated in this study are different from those in our previous experiments showing that forced use of the impaired forelimb causes adverse effects in rats with focal cortical lesions or ischemic injury confined to the sensorimotor cortex (Kozlowski et al., 1996; Humm et al., 1998, 1999; Risedal et al., 1999; Bland et al., 2000). However, there are several variables that differ between our previous findings and our current results, such as the rate of 
the injury, primary and secondary degenerative events, and the location of the injury. Indeed, when ischemic damage included the striatum, forced use of the affected forelimb did not exaggerate the extent of the damage (Bland et al., 2001). In addition, there are precedents for beneficial effects of physical therapy in both stroke and PD patients (Bilowit, 1956; Szekely et al., 1982; Comella et al., 1994; Taub et al., 1999; Liepert et al., 2000; de Goede et al., 2001). Finally, the detrimental behavioral effects of decreased activity in unilateral 6-OHDA-treated rats is analogous to our findings in rats with ischemic injury that were forced to not use the affected forelimb (Bland et al., 2001).

Our findings suggest three points that may be important for PD patients. First, we have shown that decreased physical activity actually exacerbated the neurodegenerative process in unilateral PD rats. Second, we again found that increased physical activity during the degenerative process attenuated both the behavioral deficit and the loss of striatal DA. Finally, we demonstrated that the effects of nonuse could reverse the effects of forced use even when the period of inactivity was separated from the period of use by as much as 2 weeks. This suggests that although exercise can be neuroprotective, those effects are not necessarily permanent and apparently must be maintained by continuous exercise or normal use. Overall, these results demonstrate the role of decreased physical activity in the perpetuation of behavioral and neurochemical loss in the 6-OHDA model of PD and thus suggest that a similar reciprocal interaction between decreased physical activity and ongoing DA neuron degeneration may occur in PD.

\section{REFERENCES}

Bilowit DS (1956) Establishing physical objectives in rehabilitation of patients with Parkinson's disease (gymnasium activities). Phys Ther Rev 36:176-178.

Bland ST, Schallert T, Strong R, Aronowski J, Grotta JC, Feeney DM (2000) Early exclusive use of the affected forelimb after moderate transient focal ischemia in rats: functional and anatomic outcome. Stroke 31:1144-1152.

Bland ST, Pillai RN, Aronowski J, Grotta JC, Schallert T (2001) Early overuse and disuse of the affected forelimb after moderately severe intraluminal suture occlusion of the middle cerebral artery in rats. Behav Brain Res 126:33-41.

Bury SD, Eichhorn AC, Kotzer CM, Jones TA (2000) Reactive astrocytic responses to denervation in the motor cortex of adult rats are sensitive to manipulations of behavioral experience. Neuropharmacology 39:743-755.

Carro E, Trejo JL, Busiguina S, Torres-Aleman I (2001) Circulating insulin-like growth factor I mediates the protective effects of physical exercise against brain insults of different etiology and anatomy. J Neurosci 21:5678-5684.

Cohen AD, Tillerson JL, Moroz I, Zigmond MJ, Smith AD, Austin M, Stewart J, Schallert T (2001) Spared function in the unilateral 6-OHDA lesioned rat by pre-surgical forced use of the impaired forelimb: possible role for trophic factors. Soc Neurosci Abstr 27:430.20.

Comella CL, Stebbins GT, Brown-Toms N, Goetz CG (1994) Physical therapy and Parkinson's disease: a controlled clinical trial. Neurology 44:376-378.

Czurko A, Hirase H, Csicsvari J, Buzsaki G (1999) Sustained activation of hippocampal pyramidal cells by "space clamping" in a running wheel. Eur J Neurosci 11:344-352.

de Goede CJ, Keus SH, Kwakkel G, Wagenaar RC (2001) The effects of physical therapy in Parkinson's disease: a research synthesis. Arch Phys Med Rehabil 82:509-515.

Fertl E, Doppelbauer A, Auff E (1993) Physical activity and sports in patients suffering from Parkinson's disease in comparison with healthy seniors. J Neural Transm Park Dis Dement Sect 5:157-161.

Franklyn S, Kohout LJ, Stern GM, Dunning M (1981) Physiotherapy in Parkinson's disease. In: Research progress in Parkinson's disease (Rose FC, Capiledo R, eds), pp 397-400. Tunbridge Wells, UK: Pittman.

Gomez-Pinilla F, Dao L, So V (1997) Physical exercise induces FGF-2 and its mRNA in the hippocampus. Brain Res 764:1-8.

Gomez-Pinilla F, So V, Kesslak JP (1998) Spatial learning and physical activity contribute to the induction of fibroblast growth factor: neural substrates for increased cognition associated with exercise. Neuroscience 85:53-61.

Humm JL, Kozlowski DA, James DC, Gotts JE, Schallert T (1998)
Use-dependent exacerbation of brain damage occurs during an early post-lesion vulnerable period. Brain Res 783:286-292.

Humm JL, Kozlowski DA, Bland ST, James DC, Schallert T (1999) Use-dependent exaggeration of brain injury: is glutamate involved? Exp Neurol 157:349-358.

Hurwitz A (1989) The benefit of a home exercise regimen for ambulatory Parkinson's disease patients. J Neurosci Nurs 21:180-184.

Jones TA, Schallert T (1994) Use-dependent growth of pyramidal neurons after neocortical damage. J Neurosci 14:2140-2152.

Knott M (1957) Report of case of parkinsonism treated with proprioceptive facilitation techniques. Phys Ther Rev 37:229.

Kozlowski DA, James DC, Schallert T (1996) Use-dependent exaggeration of neuronal injury after unilateral sensorimotor cortex lesions. J Neurosci 16:4776-4786.

Lees AJ (1992) When did Ray Kennedy's Parkinson's disease begin? Mov Disord 7:110-116.

Liepert J, Bauder H, Wolfgang HR, Miltner WH, Taub E, Weiller C (2000) Treatment-induced cortical reorganization after stroke in humans. Stroke 31:1210-1216.

Lindner MD, Plone MA, Francis JM, Blaney TJ, Salamone JD, Emerich DF (1997) Rats with partial striatal dopamine depletions exhibit robust and long-lasting behavioral deficits in a simple fixed-ratio barpressing task. Behav Brain Res 86:25-40.

Mazzoni P, Ford B (1999) The freezing of time as a presenting symptom of Parkinson's disease. N Engl J Med 341:1317-1318.

Meeusen R, De Meirleir K (1995) Exercise and brain neurotransmission. Sports Med 20:160-188.

Miller GW, Levey AI (2001) Immunochemical analysis of dopamine transporters in Parkinson's disease. In: Methods in molecular medicine (Mouradian MM, ed), pp 167-177. Totowa, NJ: Humana.

Miller GW, Staley JK, Heilman CJ, Perez JT, Mash DC, Rye DB, Levey AI (1997) Immunochemical analysis of dopamine transporter protein in Parkinson's disease. Ann Neurol 41:530-539.

Miller GW, Erickson JD, Perez JT, Penland SN, Mash DC, Rye DB, Levey AI (1999) Immunochemical analysis of vesicular monoamine transporter (VMAT2) protein in Parkinson's disease. Exp Neurol 156:138-148.

Neeper SA, Gomez-Pinilla F, Choi J, Cotman C (1995) Exercise and brain neurotrophins. Nature 373:109.

Olanow CW, Tatton WG (1999) Etiology and pathogenesis of Parkinson's disease. Annu Rev Neurosci 22:123-144.

Palmer SS, Mortimer JA, Webster DD, Bistevins R, Dickinson GL (1986) Exercise therapy for Parkinson's disease. Arch Phys Med Rehabil 67:741-745.

Risedal A, Zeng J, Johansson BB (1999) Early training may exacerbate brain damage after focal brain ischemia in the rat. J Cereb Blood Flow Metab 19:997-1003.

Schallert T, Hall S (1988) "Disengage" sensorimotor deficit following apparent recovery from unilateral dopamine depletion. Behav Brain Res 30:15-24.

Schallert T, Tillerson JL (2000) Intervention strategies for degeneration of dopamine neurons in parkinsonism: optimizing behavioral assessment of outcome. In: Central nervous system diseases (Emerich DF, Dean RLI, Sanberg PR, eds), pp 131-151. Totowa, NJ: Humana.

Schallert T, Norton D, Jones TA (1992a) A clinically relevant unilateral rat model of Parkinsonian akinesia. J Neural Transplant Plasticity 3:332-333.

Schallert T, Jones TA, Weaver M, Shapiro L, Crippens D, Fulton R (1992b) Pharmacologic and anatomic considerations in recovery of function. In: Neuropsychological assessment-physical medicine and rehabilitation: state of the art reviews (Hanson S, Tucker DM, eds), pp 375-393. Philadelphia: Hanley and Belfus.

Schallert T, Fleming SM, Leasure JL, Tillerson JL, Bland ST (2000) CNS plasticity and assessment of forelimb sensorimotor outcome in unilateral rat models of stroke, cortical ablation, parkinsonism and spinal cord injury. Neuropharmacology 39:777-787.

Sharpe LG, Pilotte NS, Mitchell WM, De Souza EB (1991) Withdrawal of repeated cocaine decreases autoradiographic $[3 \mathrm{H}]$ mazindol-labelling of dopamine transporter in rat nucleus accumbens. Eur J Pharmacol 203:141-144.

Stewart J, Moroz I, Cohen AD, Tillerson JL, Martinez E, Schallert T (2001) Effects of forced limb use on behavioral outcome and expression of FGF-2 after partial unilateral 6-OHDA lesions of nigrostriatal dopamine neurons. Soc Neurosci Abstr 27:430.21.

Stroemer RP, Kent TA, Hulsebosch CE (1995) Neocortical neural sprouting, synaptogenesis, and behavioral recovery after neocortical infarction in rats. Stroke 26:2135-2144.

Swinnen SP, Steyvers M, Van Den Bergh L, Stelmach GE (2000) Motor learning and Parkinson's disease: refinement of within-limb and between-limb coordination as a result of practice. Behav Brain Res 111:45-59.

Szekely BC, Kosanovich NN, Sheppard W (1982) Adjunctive treatment in Parkinson's disease: physical therapy and comprehensive group therapy. Rehabil Lit 43:72-76.

Taub E, Uswatte G, Pidikiti R (1999) Constraint-induced movement 
therapy: a new family of techniques with broad application to physical rehabilitation - a clinical review. J Rehabil Res Dev 36:237-251.

Tillerson JL, Cohen AD, Philhower J, Miller GW, Zigmond MJ, Schallert $\mathrm{T}$ (2001) Forced limb-use effects on the behavioral and neurochemical effects of 6-hydroxydopamine. J Neurosci 21:4427-4435.

Toole T, Hirsch MA, Forkink A, Lehman DA, Maitland CG (2000) The effects of a balance and strength training program on equilibrium in Parkinsonism: a preliminary study. Neurorehabilitation 14:165-174.

Toth MJ, Fishman PS, Poehlman ET (1997) Free-living daily energy expenditure in patients with Parkinson's disease. Neurology 48:88-91.

Ungerstedt U (1971) Postsynaptic supersensitivity after 6-hydroxydopamine induced degeneration of the nigro-striatal dopamine system. Acta Physiol Scand Suppl 367:69-93.

van Praag H, Christie BR, Sejnowski TJ, Gage FH (1999) Running enhances neurogenesis, learning, and long-term potentiation in mice. Proc Natl Acad Sci USA 96:13427-13431.

Whishaw IQ (2000) Loss of the innate cortical engram for action patterns used in skilled reaching and the development of behavioral compensation following motor cortex lesions in the rat. Neuropharmacology 39:788-805.

Widenfalk J, Olson L, Thoren P (1999) Deprived of habitual running, rats downregulate BDNF and TrkB messages in the brain. Neurosci Res 34:125-132.
Wilson JM, Kalasinsky KS, Levey AI, Bergeron C, Reiber G, Anthony RM, Schmunk GA, Shannak K, Haycock JW, Kish SJ (1996a) Striatal dopamine nerve terminal markers in human, chronic methamphetamine users. Nat Med 2:699-703.

Wilson JM, Levey AI, Bergeron C, Kalasinsky K, Ang L, Peretti F, Adams VI, Smialek J, Anderson WR, Shannak K, Deck J, Niznik HB, Kish SJ (1996b) Striatal dopamine, dopamine transporter, and vesicular monoamine transporter in chronic cocaine users. Ann Neurol $40: 428-439$.

Zigmond MJ (1997) Do compensatory processes underlie the preclinical phase of neurodegenerative disease? Insights from an animal model of parkinsonism. Neurobiol Dis 4:247-253.

Zigmond MJ, Burke RE (2002) Pathophysiology of parkinson's disease. In: Fifth generation of progress (Davis KL, Coyle J, Charney D, Nemeroff C, eds), pp 1781-1794. American College of Neuropsychopharmacology. Philadelphia: Lippincott, Williams and Wilkens.

Zigmond MJ, Stricker EM (1989) Animal models of parkinsonism using selective neurotoxins: clinical and basic implications. Int Rev Neurobiol $31: 1-79$.

Zigmond MJ, Acheson AL, Stachowiak MK, Stricker EM (1984) Neurochemical compensation after nigrostriatal bundle injury in an animal model of preclinical parkinsonism. Arch Neurol 41:856-861. 